\title{
Penerapan Algoritma K-Means Untuk Clustering Penilaian Dosen Berdasarkan Indeks Kepuasan Mahasiswa
} Application of K-Means Algorithm for Clustering Lecturer Based On Assessment of Student Satisfaction Index

\author{
Aldi Nurzahputra ${ }^{* 1}$, Much Aziz Muslim ${ }^{2}$, Miranita Khusniati ${ }^{3}$, \\ ${ }^{1,2}$ Jurusan Ilmu Komputer, FMIPA, Universitas Negeri Semarang \\ ${ }^{3}$ Jurusan Ilmu Pengetahuan Alam, FMIPA, Universitas Negeri Semarang \\ Jalan Taman Siswa, Sekaran, GunungPati, Semarang, 50229 \\ e-mail: *12aldinurzah96@gmail.com, ${ }^{2}$ a212muslim@yahoo.com, ${ }^{3}$ miranita@mail.unnes.ac.id,
}

\begin{abstract}
Abstrak
Dalam lingkup perguruan tinggi, aktivitas penilaian kinerja juga diterapkan untuk menilai kinerja dosen. Dasar yang digunakan dalam penilaian tersebut menggunakan dasar tri dhrama perguruan tinggi. Dalam penilaian kinerjanya, diperlukan data terkait kepuasan mahasiswa terhadap dosen. Data yang digunakan dalam penelitian ini adalah data kepuasan mahasiswa jurusan Ilmu Pengetahuan Alam, FMIPA, UNNES, berjumlah 146 untuk semua dosen di prodi yang berjumlah 12 dosen. Dalam pengambilan data menggunakan kuesioner dari Badan Penjaminan Mutu Unnes. Varibale yang digunakan (1) kehandalan dosen (reliability); (2) sikap tanggap (responsiveness); (3) jaminan (assurance); dan (4) empati (empathy). Data akan diolah dengan melakukan clustering kinerja dosen dalam cluster baik, atau kurang. Metode clustering yang digunakan dalam penelitian ini adalah metode K-Means. Cetroid data untuk cluster_baik 17.099 dan cluster_kurang 15.874. Sehingga diperoleh penilaian dosen berdasarkan indeks kepuasan mahasiswa dengan 5 dosen cluster_baik dan 7 dosen_cluster kurang. Hasil yang dari penelitian dapat digunakan untuk meningkatkan kinerja dosen dalam mengajar untuk meningkatkan indeks kepuasan mahasiswa.
\end{abstract}

Kata kunci-Clustering, K-Means, Data Mining, Penilaian Dosen

\begin{abstract}
In the scope of higher education, performance appraisal activity is also applied to assess the performance of lecturers. The base that used in the assessment is Three Pillars of Higher Education. In the performance evaluation is needed student satisfaction data related to lecturers. The data used in this study is data of student satisfaction in Natural Sciences departement, UNNES, numbering 146 for all lecturers in the study program to 12 lecturers. In collecting data is using questionnaires from the Quality Assurance Agency, UNNES. The varibale are (1) reliability lecturer; (2) responsiveness; (3) a guarantee; and (4) empathy. The data will be processed by clustering in two clusters, cluster_baik (good) and cluster_kurang (less). In this research use K-Means Clustering as the method. By clustering the data, we get the cetroid for cluster_baik is 17.099 and cluster_kurang is 15.874. It obtained performance of lecturers based on student satisfaction index with lecturer cluster_baik are 5 lecturers and there are 7 lecturers in cluster_less. The results of the research could be used to improve the performance of lecturers in teaching to improve student satisfaction index.
\end{abstract}

Keywords - Clustering, K-Means, Data Mining, Lecturers Performance

\section{PENDAHULUAN}

Saat ini, aktivitas penilaian terhadap kinerja setiap karyawan menjadi aktivitas yang umum dilakukan oleh suatu organisasi maupun instansi. Penilaian kinerja (performance appraisal) adalah suatu proses yang digunakan pimpinan untuk menentukan apakah seorang karyawan melakukan 
pekerjaannya sesuai dengan tugas dan tanggung jawabnya [1]. Penilaian kinerja juga berlaku dalam perguruan tinggi, baik itu berupa universitas, institut, maupun sekolah tinggi.

Dalam lingkup perguruan tinggi, aktivitas penilaian kinerja juga diterapkan untuk menilai kinerja dosen, staff, dan mahasiswa. Dasar yang digunakan dalam penilaian tersebut menggunakan dasar tri dhrama perguruan tinggi. Undang-Undang Nomor 20 Tahun 2003 tentang Sistem Pendidikan Nasional menyebutkan bahwa perguruan tinggi berkewajiban menyelenggarakan pendidikan, penelitian, dan pengabdian kepada masyarakat [2].

Dosen harus mempunyai kualifikasi yang diperlukan bagi penyampaian ilmunya kepada mahasiswa [3]. Dosen berkewajiban mengelola sumber daya manusia yang dibutuhkan untuk mengimplementasikan sistem manajemen mutu yang dilakukan secara berkelanjutan agar dapat efektif dan efisien dalam mencapai kualitas pendidikan yang telah ditetapkan. Dengan tenaga dosen yang mempunyai kualitas dan berkompeten akan memudahkan dalam penyampaian ilmu pengetahuan dan teknologi. Kaitannya dengan kualifikasi ini, seorang dosen senantiasa minimal telah mendapat penyetaraan jabatan fungsional dari Departemen Pendidikan Nasional, dengan jabatan Asisten Ahli. Semakin tinggi jabatan fungsional dosen menunjukkan tingkat kualifikasinya baik dari aspek prestasi maupun prestisienya.

Dalam menilai kinerja dosen dapat didasarkan pada tri dharma perguruan tinggi, salah satunya pendidikan terkait pengajaran. Oleh karena itu, diperlukan data pendukung salah satunya yaitu melalui kepuasan mahasiswa terhadap kinerja dosen khususnya dalam proses pendidikan dan pengajaran. Pengolahan data tersebut dapat dilakukan dengan data mining. Data akan diolah dengan melakukan clustering kinerja dosen dalam cluster baik, atau kurang.

Endang Sugiharti [3] pada penelitiannya melakukan clustering data dosen terkait kegiatan dan kinerjanya sesuai dengan pelaksanaan dan tanggung jawab meggunanakan metode K-Means. Cluster dalam penelitian tersebut kedalam cluster Networking, Software Engineering, dan E-Learning.

Metode clustering yang digunakan dalam penelitian ini adalah metode K-Means. K-Means dapat juga diartikan merupakan metode Clustering yang termasuk dalam pendekatan partitioning. Algoritma K-Means merupakan model centroid. Mode centroid adalah model yang menggunakan centroid untuk membuat cluster. Centroid adalah titik tengah suatu cluster. Centroid berupa nilai. Centroid digunakan untuk menghitung jarak suatu objek data terhadap centroid. Suatu objek data termasuk dalam cluster jika memiliki jarak terpendek terhadap centroid cluster tersebut. Algoritma K-Means dapat diartikan sebagai algoritma pembelajaran yang sederhana untuk memecahkan suatu permasalahan pengelompokkan yang bertujuan untuk meminimalkan kesalahan ganda [4].

Tujuan dari penelitian ini adalah menerapkan k-means dalam mengcluster kinerja dosen berdasarkan indeks kepuasan mahasiswa.

\section{METODE}

Dalam penelitian ini metode yang digunakan yaitu metode data mining [5] sebagai berikut. (a) Tahap pengumpulan data, (b) Tahap pengolahan data, (c) Tahap Clustering dan (d) Tahap Analisis. Tahapan dalam metode tersebut dijelaskan lebih lanjut sebagai berikut:

\section{Tahap Pengumpulan Data}

Dalam penilaian kinerjanya, diperlukan data terkait kepuasan mahasiswa terhadap dosen. Data yang digunakan dalam penelitian ini adalah data kepuasan mahasiswa jurusan Ilmu Pengetahuan Alam, FMIPA, UNNES, berjumlah 146 untuk semua dosen di prodi yang berjumlah 12, sehingga tiap dosen terlihat kinerjanya. Dalam pengambilan data menggunakan kuesioner dari Badan Penjaminan Mutu Unnes yaitu FM-02-BPM-05 Form kuesioner kepuasan mahasiswa yang dimodifikasi. Varibale yang digunakan (1) kehandalan dosen (reliability); (2) sikap tanggap (responsiveness); (3) jaminan (assurance); dan (4) empati (empathy) sebagai indeks kepuasan mahasiswa terhadap dosen. 


\section{Tahap Pengolahan Data}

Data yang telah diperolah akan diolah terlebih dahulu untuk dapat diclustering. Dalam tahap sebelumnya, data setiap dosen akan dijumlah setiap aspeknya sehingga pada tahapan ini sudah diperoleh perhitungan nilai berdasarakan indeks kepuasan mahasiswa.

\section{Tahap Clustering}

Clustering merupakan klasifikasi tanpa pengawasan dan merupakan proses partisi sekumpulan objek data dari satu set menjadi beberapa kelas. Hal ini dapat dilakukan dengan menerapkan berbagai persamaan dan langkah-langkah mengenai jarak algoritma, yaitu dengan Euclidean Distance [6]. Analisis kluster ialah metode yang dipakai untuk membagi rangkaian data menjadi beberapa grup berdasarkan kesamaan-kesamaan yang telah ditentukan sebelumnya [3].

Dalam menentukan cluster berdasarkan data yang telah tersedia, dibutuhkan sebuah flowchart untuk memudahkan dalam menentukan alur perhitungan sebagai alur untuk menemukan hasil dari penerapan cluster terhadap data yang akan diproses. Berikut adalah flowchart dalam menentukan cluster dengan K-Means [7].

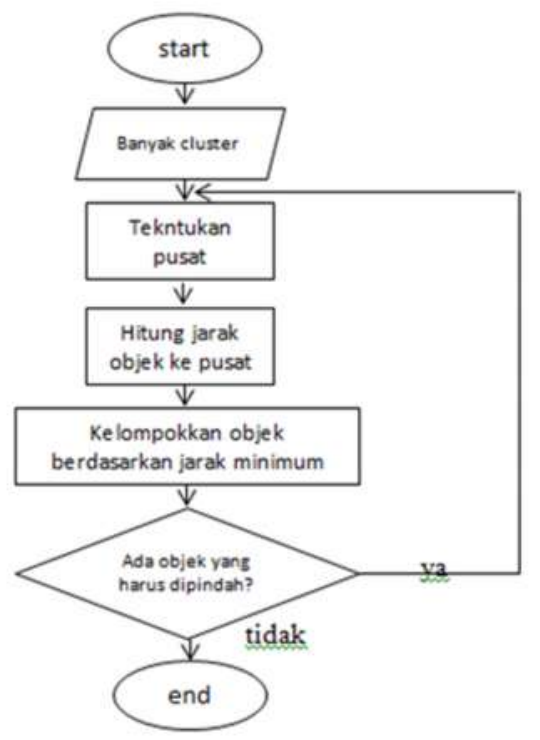

Gambar 1. Flowchart K-Means

\section{Tahap Analisis}

Pada tahapan ini dilakukan analisis data kinerja dosen berdasarakan indeks kepuasan mahasiswa menggunakan aplikasi tool. Rapid Minner. RapidMiner adalah sebuah lingkungan machine learning data mining, text mining dan predictive analytics [8]. Data yang diperoleh dari kuisioner diolah dengan menggunakan perhitungan bobot dari tiap indeks kepuasan. Pada tahapan sebelumnya, telah ditentukan akan dicluster ke dalam 2 cluster yakni cluster_baik dan cluster_kurang. Pada tahapan inilah akan dianalisis hasilnya.

\section{HASIL DAN PEMBAHASAN}

Dalam melakukan clustering, data yang diperoleh akan dihitung terlebih dahulu berdasarkan bobot yang telah ditentukan. Data akan dihitung sehingga didapatkan data yang siap dicluster.

Data penilaian dosen diberikan kepada 146 responden yakni mahasiswa jurusan Ilmu Pengetahuan Alam terhadap 12 dosen. Berikut data setiap Aspek untuk penilian satu dosen disajikan dalam tabel 1 sampai tabel 4 :

Tabel 1. Data Aspek Reliability

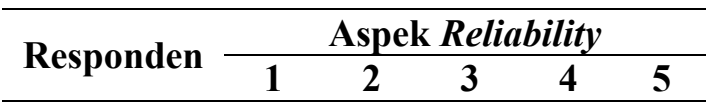




\begin{tabular}{cccccc}
\hline 1 & 4 & 5 & 3 & 4 & 5 \\
2 & 3 & 3 & 4 & 3 & 3 \\
3 & 4 & 4 & 5 & 4 & 5 \\
. &. &. &. &. &. \\
146 & 4 & 4 & 4 & 4 & 4 \\
\hline
\end{tabular}

Tabel 2. Data Aspek Responsiveness

\begin{tabular}{llllll}
\hline \multirow{2}{*}{ Responden } & \multicolumn{5}{c}{ Aspek Responsiveness } \\
\cline { 2 - 6 } & $\mathbf{1}$ & $\mathbf{2}$ & $\mathbf{3}$ & $\mathbf{4}$ & $\mathbf{5}$ \\
\hline 1 & 5 & 5 & 5 & 4 & 3 \\
2 & 3 & 3 & 3 & 3 & 3 \\
3 & 5 & 5 & 4 & 5 & 3 \\
. &. &. &. &. &. \\
146 & 4 & 4 & 4 & 4 & 4 \\
\hline
\end{tabular}

Tabel 3. Data Aspek Assurance

\begin{tabular}{cccccc}
\hline \multirow{2}{*}{ Responden } & \multicolumn{5}{c}{ Aspek Assurance } \\
\cline { 2 - 6 } & $\mathbf{1}$ & $\mathbf{2}$ & $\mathbf{3}$ & $\mathbf{4}$ & $\mathbf{5}$ \\
\hline 1 & 5 & 3 & 4 & 5 & 4 \\
2 & 3 & 3 & 3 & 4 & 3 \\
3 & 5 & 4 & 4 & 4 & 3 \\
. &. &. &. &. &. \\
146 & 4 & 4 & 4 & 4 & 4 \\
\hline
\end{tabular}

Tabel 4. Data Aspek Empathy

\begin{tabular}{cccccc}
\hline \multirow{2}{*}{ Responden } & \multicolumn{5}{c}{ Aspek Empathy } \\
\cline { 2 - 6 } & $\mathbf{1}$ & $\mathbf{2}$ & $\mathbf{3}$ & $\mathbf{4}$ & $\mathbf{5}$ \\
\hline 1 & 5 & 4 & 5 & 4 & 4 \\
2 & 3 & 4 & 3 & 3 & 3 \\
3 & 4 & 3 & 5 & 5 & 3 \\
. &. &. &. &. &. \\
146 & 4 & 4 & 4 & 4 & 4 \\
\hline
\end{tabular}

Data tersebut kemudian diakumulasikan dari reponden 1 sampai responden 146 kemudian dilakukan perhitungan untuk setiap sub 1 sampai 5 di setiap aspek. Kemudian dari hasil tersebut, dihitung rata-rata untuk setiap aspek untuk mendapatkan nilai dari satu dosen tersebut. Berikut tabel akumulasi data hasil disajikan pada tabel 5 berikut:

Table 5. Akumulasi Perhitungan Nilai

\begin{tabular}{|c|c|c|c|c|}
\hline $\begin{array}{c}\text { Indeks } \\
\text { Kepuasan }\end{array}$ & \multicolumn{2}{|c|}{ Jumlah } & $\begin{array}{l}\text { Rata- } \\
\text { rata }\end{array}$ & Nilai \\
\hline & 1 & 610 & 4.1 & \multirow{6}{*}{16.15} \\
\hline \multirow{4}{*}{ Reliability } & 2 & 605 & & \\
\hline & 3 & 599 & & \\
\hline & 4 & 555 & & \\
\hline & 5 & 627 & & \\
\hline Aspek & 1 & 607 & 4.1 & \\
\hline
\end{tabular}




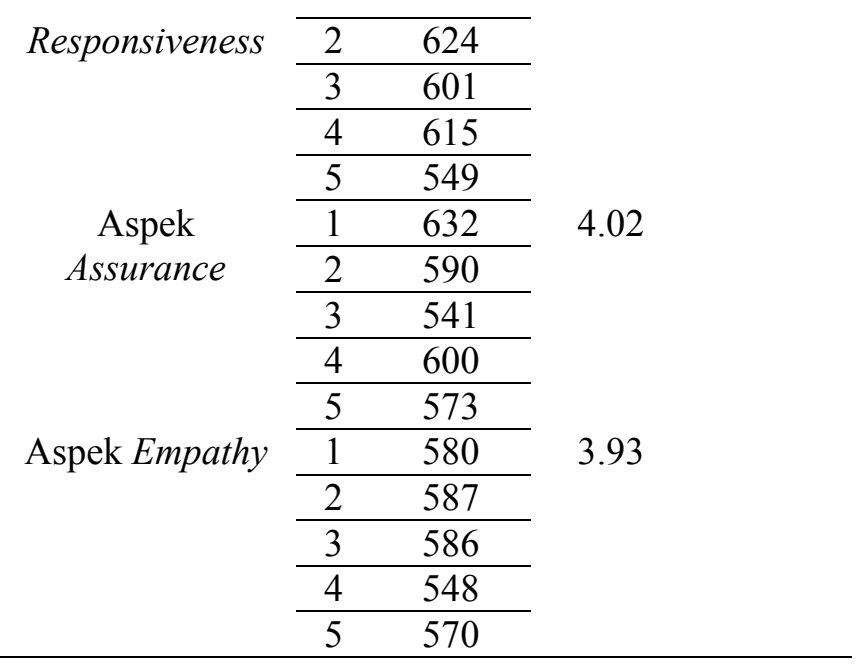

Setelah diakumulasikan maka akan didapatkan nilai dari seleuruh data dosen. Kemudian data tersebut akan masuk ke tahaoan clustering dengan menerapkan algoritma K-Means menggunakan rapid minner untuk mengcluster data menjadi dua cluster.

Penerapan algoritma K-Means dapat digunakan untuk mengcluster penilaian kinerja dosen. Dalam penelitian ini, data yang telah dihitung dicluster ke dalam dua cluster, yakin cluster_baik dan cluster_kurang.

\subsection{Input Data}

Data yang telah diakumulasikan akan dimasukan ke dalam tool Rapid Minner. Sehingga dapat diclustering menjadi dua. Setelah dimasukan ke dalam Rapid Minner. Hasil akumulais data dapat disajikan dalam tabel 6 berikut:

Tabel 6. Nilai Dosen

\begin{tabular}{cc}
\hline Id & Nilai \\
\hline 1 & 16.15 \\
2 & 14.70 \\
3 & 16.36 \\
4 & 17.10 \\
5 & 16.57 \\
6 & 17.45 \\
7 & 16.06 \\
8 & 16.36 \\
9 & 17.58 \\
10 & 15.65 \\
11 & 16.80 \\
12 & 15.82 \\
\hline
\end{tabular}

Data tersebut dimasukan ke dalam tool, kemudian dilakukan pemetaan data 12 dosen tersebut, input data tersebut dapat disajikan dalam gambar 2. 


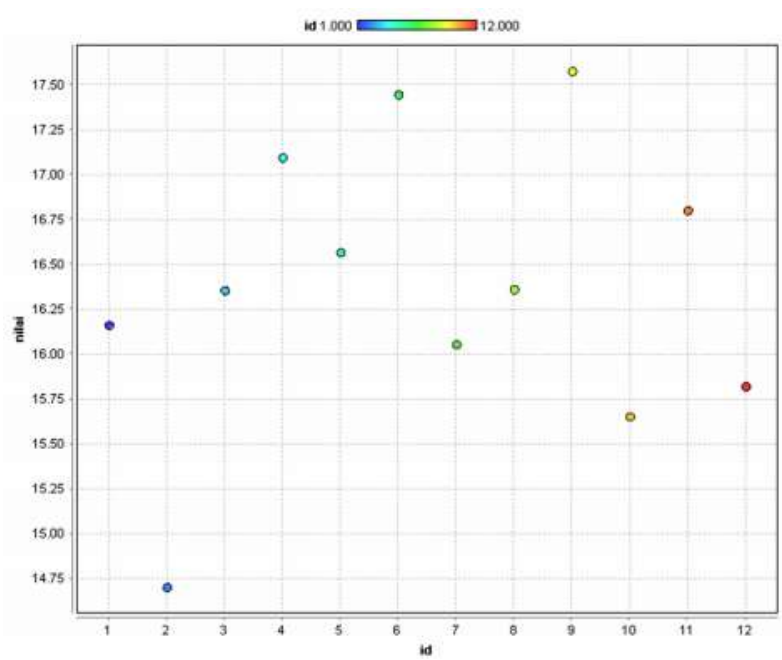

Gambar 2. Data Input

\subsection{Centroid Data}

Dalam penerapan algoritma K-means dihasilkan nilai titik tengah atau centroid dari data yang didapat dengan ketentuan bahwa clusterisasi yang diinginkan adalah 2, maka nilai titik tengah atau centroid juga terdapat 2 titik. Nilai titik tengah atau centroid dapat diketahui pada Tabel 7 berikut:

Tabel 3. Centroid Data Untuk Cluster_Baik dan Cluster_Kurang

\begin{tabular}{ccc}
\hline Artibut & Cluster_baik & Cluster_kurang \\
\hline Nilai & 17.099 & 15.874 \\
\hline
\end{tabular}

\subsection{Clustering Data}

Dengan menggunakan centroid tersebut maka dapat dicluster data yang telah didapat menjadi 2 cluster. Dari data dosen berdasarakan indeks kepuasaan mahasiswa didapatakan 7 dosen dalam cluster_kurang dan 5 dosen dalam cluster_baik. Clustering data dapat digambarkan pada gambar 3 berikut:

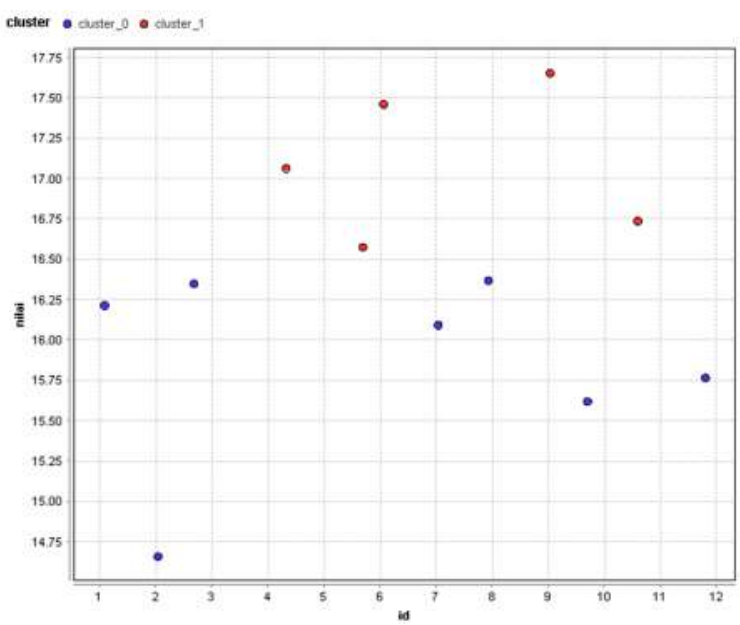

Gambar 3. Clustering Data

Sehingga telah didapatkan hasil clustering data. Clustering tersebut dapat dilihat lebih jelas dengan menerapkan centorid yang didapatkan pada hasil yang sebelumnya.

\subsection{Analisis}


Dari 12 data dosen dapat dikertahui, 5 dosen masuk dalam cluster_baik dan 7 dosen masuk dalam cluster_kurang. Data tersebut dapat digunkan untuk varibel penilai dosen berdasarkan indeks kepuasan mahasiswa dalam kenaikan jabatan.

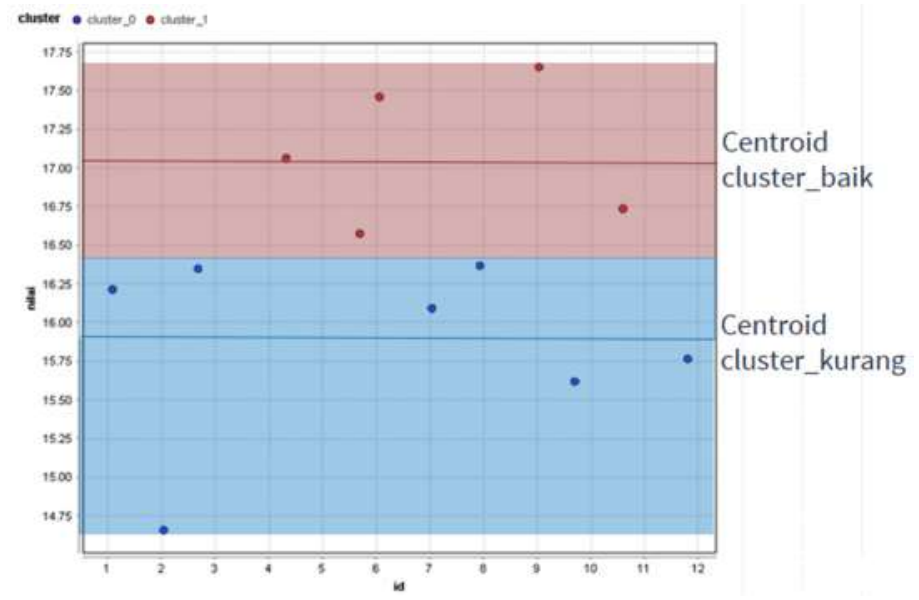

Gambar 4. Hasil Clustering

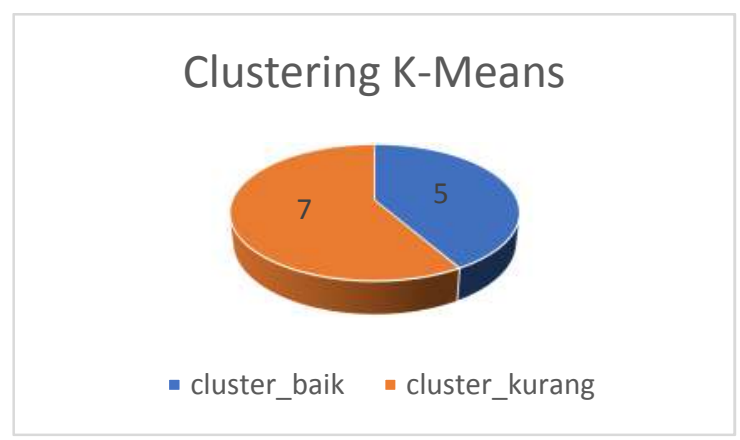

Gambar 5. Clustering Penilaian Dosen Berdasarkan Indeks Kepuasan Mahasiswa

\section{KESIMPULAN}

Untuk melakukan penilaian kinerja dosen berdasarakan indeks kepuasan mahasiswa dapat menerapkan metode clustering K-Means. Data diperoleh dari mahasiswa melalui kuisioner sesuai aspek Reliability, Responsiveness, Assurance, dan Empathy. Data diolah untuk memperolah nilai dari setiap dosen. Data kemudian diolah menggunakan Rapidminner untuk ditentukan nilai centroid dalam cluster_baik dan cluster_kurang dengan algoritma K-Means. Cetroid data untuk cluster_baik 17.099 dan cluster_kurang 15.874. Sehingga diperoleh penilaian dosen berdasarakan indeks kepuasan mahasiswa dengan 5 dosen cluster_baik dan 7 dosen_cluster kurang.

\section{SARAN}

Dalam pengolahan data untuk clustering bisa memberikan pembobotan kriteria agar data yang dihasilkan lebih akurat. Selain itu, juga perlu meningkatan akurasi clustering pada data.

\section{UCAPAN TERIMA KASIH}

Terima kasih kepada Jurusan Ilmu Pengetahuan Alam dan Ilmu Komputer FMIPA, Universitas Negeri Semarang atas dukungan dalam terlaksanakannya penelitian ini. 


\section{DAFTAR PUSTAKA}

[1] Magkunegara, Anwar. AA., 2011, Manajemen Sumber Daya Manusia Perusahaan, Penerbit Remaja Rosda Karya, Bandung.

[2] Undang-Undang Nomor 20 Tahun 2003 tentang Sistem Pendidikan Nasional.

[3] Sugiharti, E., \& Muslim, M. A., 2016, On-line Clustering of Lecturers Performance of Computer Science Department of Semarang State University Using K-Means Algorithm, Journal of Theoretical and Applied Information Technology, 83(1).

[4] Singla, A., \& Karambir, M., 2012, Comparative Analysis \& Evaluation of Euclidean Distance Function and Manhattan Distance Function Using K-Means Algorithm, International Journal of Advanced Research in Computer Science and Software Engineering (IJARSSE), 2(7), 298-300.

[5] Prasetyo, E., 2014, Data Mining Mengolah Data Menjadi Informasi Menggunakan Matlab, Yogyakarta, Penerbit ANDI.

[6] Venkateswarlu, B., \& Raju, P. G., 2013, Mine Blood Donors Information through Improved KMeans Clustering, arXiv preprint arXiv:1309.2597.

[7] Hermawati, F. A., 2013, Data Mining, Penerbit ANDI, Yogyakarta.

[8] Soni, N., \& Ganatra, A., 2012, Categorization of several Clustering algorithms from different perspective: a review, International Journal of Advanced Research in Computer Science and Software Engineering, 2(8), 63-68. 